\title{
Phase I dose-escalation study of pazopanib combined with bevacizumab in patients with metastatic renal cell carcinoma or other advanced tumors
}

Sylvie Négrier ${ }^{1 *}$, David Pérol$^{2}$, Rastislav Bahleda ${ }^{3}$, Antoine Hollebecque $^{3}$, Etienne Chatelut $^{4}$, Helen Boyle $^{5}$, Philippe Cassier ${ }^{5}$, Séverine Metzger ${ }^{5}$, Ellen Blanc ${ }^{5}$, Jean-Charles Soria ${ }^{6}$ and Bernard Escudier ${ }^{7}$

\begin{abstract}
Background: Vascular endothelial growth factor (VEGF) directed therapies are being used in a large number of advanced tumors. Metastatic renal cell carcinoma (mRCC) is highly dependent on the VEGF pathway; VEGF receptor (VEGFR) tyrosine kinase inhibitors (TKI) and humanized VEGF monoclonal antibody have been registered for clinical use in advanced renal cell carcinoma. The VEGFR TKI, pazopanib, with a rather manageable toxicity profile, was preferred to sunitinib by mRCC patients. We investigate the combination of pazopanib and bevacizumab to determine the maximum tolerated dose (MTD) in MRCC and other advanced solid tumors.

Methods: In this bicentric phase I trial with a $3+3+3$ dose-escalation design, patients received oral pazopanib once daily plus intravenous infusion of bevacizumab every 2 weeks from D15, at one of the four dose levels (DL) planned according to the occurrence of dose limiting toxicities (DLT). 400 and $600 \mathrm{mg}$ pazopanib were respectively combined with $7.5 \mathrm{mg} / \mathrm{kg}$ bevacizumab in DL1 and DL2, and 600 and $800 \mathrm{mg}$ pazopanib with $10 \mathrm{mg} / \mathrm{kg}$ bevacizumab in DL3 and DL4. Tumor response was evaluated every 8 weeks. Blood samples were assayed to investigate pazopanib pharmacokinetics.

Results: Twenty five patients including seven mRCC were enrolled. Nine patients received the DL1, ten received the DL2. No DLT were observed at DL1, five DLT at DL2, and 3 DLT in the six additional patients who received the DL1. A grade 3 microangiopathic hemolytic anemia syndrome was observed in four (16\%) patients. Five (22\%) patients achieved a partial response. The mean (range) plasmatic concentrations of 400 and 600 pazopanib were respectively 283 (139-427) and 494 (227-761) $\mu \mathrm{g} . \mathrm{h} / \mathrm{mL}$ at Day 1, and 738 (487-989) and 1071 (678-1464) $\mu \mathrm{g} . \mathrm{h} / \mathrm{mL}$ at Day 15 i.e. higher than those previously reported with pazopanib, and were not directly influenced by bevacizumab infusion.

Conclusions: The combination of pazopanib and bevacizumab induces angiogenic toxicity in patients without any pre-existing renal or vascular damage. Even if a marginal efficacy was reported with five (22\%) patients in partial response in different tumor types, the toxicity profile compromises the development of this combination.
\end{abstract}

Trial registration: The study was retrospectively registered on ClinicalTrials.gov (number NCT01202032) on 2010, Sept 14th.

Keywords: Renal carcinoma, Bevacizumab, Pazopanib, Combination Angiogenesis, Phase I trial

\footnotetext{
* Correspondence: sylvie.negrier@lyon.unicancer.fr

'University Lyon, Université Claude Bernard Lyon 1, Centre Léon Bérard,

Lyon, France

Full list of author information is available at the end of the article
} 


\section{Background}

The efficacy of an anti-VEGF antibody was originally demonstrated in renal cell carcinoma and published forteen years ago [1]. Treatments have evolved from known therapies using exclusively cytokines to therapies targeting angiogenesis, cell proliferation, and tumor growth. These recent developments have enabled tangible clinical benefits in different solid tumor types [2-5], especially in renal cell cancer, and supported subsequent development of VEGF inhibitors, mainly tyrosine kinase inhibitors (TKI) directed against VEGF receptors (VEGFR). Different agents targeting the VEGF pathway are currently registered for the treatment of advanced renal cell cancer patients [6-13]. Despite improvements observed with these targeted treatments especially in progression free survival duration, the tumor sensitivity to drugs remains limited with only scarce complete responses observed and over time resistance arises. The combination of different agents has emerged as an interesting strategy to potentially enhance the efficiency of the treatments and delay the disease's progression due to drug resistance. Combinations of VEGF inhibitors and mTor inhibitors or cytokines, administrated to patients with renal cell cancer, were acceptable in terms of tolerance but no additional gain was achieved [14-19] until recently. Indeed, the combination of lenvatinib and everolimus recently re-opened the hypothesis of a synergic combination of VEGFR and mTor inhibitors for the treatment of mRCC $[13,20]$. The combination of VEGFR TKI with a VEGF-directed antibody also looks promising but increases the treatment-related toxicity. A rather strong rational supports the combination of bevacizumab known to induce a rapid clearance of circulating VEGF, with VEGFR TKIs that mostly induce an increase of the circulating VEGF levels. High serum or plasmatic levels of VEGF were indeed previously correlated with tumor progression [18, 21-23]. The potential binding of VEGF to other receptors such as the plateletderived-growth-factor receptor (PDGFR) might also contribute to the virtually constant acquired resistance in patients treated with a VEGFR inhibitor [24]. The concomitant blockade of VEGF ligand and receptors might contribute to improve the treatment efficacy. Some of these combinations have been attempted and reported promising results in terms of efficacy but their feasibility remains as a matter of debate [14, 25-28].

Pazopanib, one of the most recently registered TKI for first-line advanced renal cancer treatment, is known to target VEGFR-1, -2 , and -3 , PDGFR- $\alpha$ and $-\beta$ as well as c-KIT [29]. Its safety profile slightly differs from that of the commonly used sunitinib. With a better tolerance reported with this multitargeted TKI, pazopanib appeared as a promising candidate to be used in combination with bevacizumab. This latter intravenous agent was also registered for treatment in metastatic renal cell cancer (mRCC) patients in combination with interferon $\alpha[7,30]$. Some activity was also demonstrated when used as monotherapy in these patients [31, 32]. Discordant results in terms of efficacy were previously reported with the combination of sunitinib and bevacizumab according to the tumor type [25, 26, 33, 34]. This phase I combination trial was consequently not only conducted in renal cell cancer patients but also in patients with other tumor types. The aim of the PARASOL trial was to test the feasibility of the combination of pazopanib with bevacizumab and to investigate pazopanib pharmacokinetics (PK).

\section{Methods \\ Patients}

Adult patients with histologically confirmed diagnosis of solid tumor excluding squamous non-small-cell lung cancer because of an increased bleeding risk [33, 34], and refractory to a maximum of two lines of standard treatments, or without prior treatment for renal cell carcinoma were eligible. Additional inclusion criteria were Eastern Cooperative Oncology Group performance status (ECOG-PS) of 0 or 1 , adequate vital functions defined as absolute neutrophil count $\geq 1500$ cells $/ \mu \mathrm{L}$, hemoglobin $\geq 9.0 \mathrm{~g} / \mathrm{dL}$, and platelets $\geq 100,000$ cells $/ \mu \mathrm{L}$, PT $\leq 1.2 x u p p e r$ limit of normal [ULN] and APTT $\leq 1.2 \mathrm{xULN}$, hepatic aspartate aminotransferase (AST) / alanine aminotransferase (ALT) $\leq 2.5 \times U L N$, total bilirubin $\leq 1.5 x U L N$, and serum creatinine $\leq 1.5 \mathrm{mg} / \mathrm{dL}$ or creatinine clearance $\geq 50 \mathrm{~mL} / \mathrm{min}$. Patients with insufficiently controlled blood pressure, increased proteinuria ( $>1.0 \mathrm{~g} / \mathrm{L})$, history of acute cardiac event, coronary disease or stroke in the previous 6 months, or corrected QT (QTc) interval prolongation (>480 ms using Bazett's formula), and patients with history of brain metastases were excluded.

The study was conducted according to the declaration of Helsinki and the International Conference of Good Clinical Practices after local approval of the Ethic Committee of Lyon Sud-Est IV and all patients provided written informed consent before enrollment. The study was registered on ClinicalTrials.gov, number NCT01202032.

\section{Study design}

This investigator-initiated phase I trial with a $3+3+3$ dose-escalation design was conducted in two institutions. Cohorts of three to nine patients were sequentially enrolled to receive one of the three escalated doses of pazopanib combined with two escalated doses of bevacizumab. The main objective was to determine the maximum-tolerated dose (MTD) of the combination in patients with advanced renal cell carcinoma or with other advanced tumors. MTD was 
defined as the highest dose level (DL) at which less than two of nine patients experienced a dose-limiting toxicity (DLT) during the first 8 weeks. Secondary objectives were the objective response rate based on RECIST 1.1 criteria [35], the 6-month progressionfree survival rate, and the pharmacokinetics (PK) of pazopanib in this combination. Cohorts of patients were enrolled in three successive steps according to the study plan shown on Fig. 1. Enrollment of nephrectomized mRCC patients were forbidden in the first step but allowed in the following steps (at least one patient in the second, and three patients in the third step). According to the independent Data and Safety Monitoring Committee (DSMB), patients enrolled at the third step of DL 2 and beyond must not have been nephrectomized. Patients were allowed to pursue the experimental treatment until tumor progression as long as the tolerance was acceptable. Safety analyses were performed after the 19th inclusion, and the steering committee, in agreement with the DSMB, recommended an extension cohort of six non-nephrectomized patients to be treated at the first dose level (400 mg pazopanib, bevacizumab $7.5 \mathrm{mg} /$ $\mathrm{kg}$ ) in order to confirm the MTD.

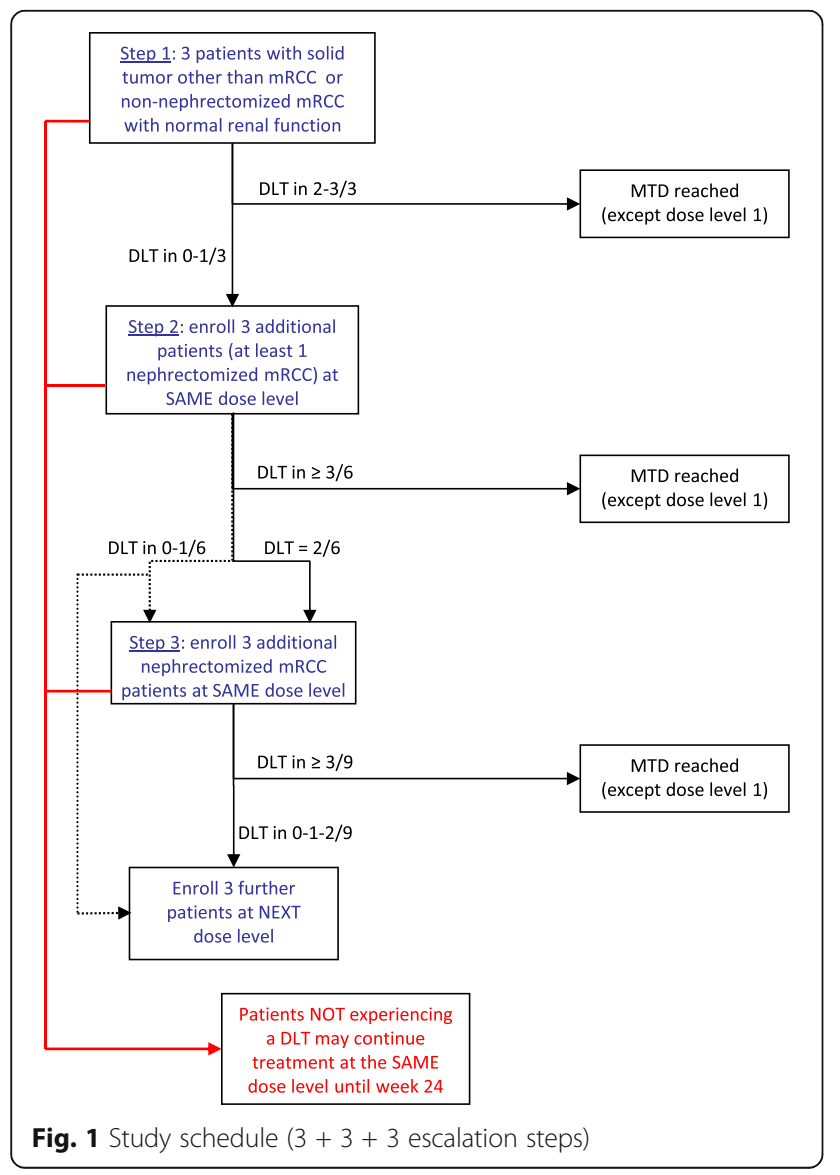

\section{Treatment and dose escalation plan}

Patients received oral pazopanib (Votrient ${ }^{\circ}$ ) (Novartis, Rueil-Malmaison, France) once daily at a dose of 400, 600 or $800 \mathrm{mg}$ per day according to the dose level plan, and intravenous bevacizumab (Avastin ${ }^{\circ}$ ) (Roche, Boulogne-Billancourt, France) at 7.5 or $10 \mathrm{mg} / \mathrm{kg}$ every 2 weeks (Q2W). Bevacizumab injections started 2 weeks after pazopanib initiation. Toxicity was assessed according to the National Cancer Institute Common Terminology Criteria for Adverse Events (CTCAE) version 3.0. Escalation to the next dose cohort was allowed following safety assessment after at least the first 8 weeks and validation by the DSMB. A DLT was considered in case of any grade 4 adverse event (AE), thrombotic $\mathrm{AE}$, grade 3 cardiac failure, non-controlled hypertension, thrombocytopenia, AST, ALT, or bilirubin level increase, or any other grade $3 \mathrm{AE}$ lasting more than 7 days except fatigue. A $200 \mathrm{mg} /$ day dose reduction of pazopanib was decided for patients experiencing a non-DLT grade 3 AE. No bevacizumab dose modification was allowed but the infusion could be delayed once. Patients requiring larger pazopanib dose reductions, or more than 4 weeks bevacizumab discontinuation were withdrawn from the study. Intra-patient dose escalation was not allowed.

\section{Tumor assessment}

Responses were assessed according to RECIST version 1.1 [35] every 8 weeks up to 24 weeks, and every 3 months thereafter. Progression free survival (PFS) was measured from the first day of pazopanib administration until the date of progression, death, or treatment discontinuation for toxicity whichever occurred first.

\section{Pharmacokinetic assessments}

Plasmatic concentration of pazopanib was centrally assessed on blood samples collected at different time points on day 1 , before treatment, at $0.5,1,2,3,4,6,8,12$, and $24 \mathrm{~h}$ after the first pazopanib administration, and on day 14 , prior to bevacizumab infusion. One serum sample was collected at week 5 and week 7 prior to bevacizumab infusions. Pharmacokinetic analyses (PK) including pazopanib area under the concentration-time curve (AUC) according to dose level, and coefficient of variation (CV\%) were performed in the Pharmacology Unit of the Institut Claudius Regaud, Toulouse, France, as previously reported [36].

\section{Statistics and data analysis}

This $3+3+3$ dose-escalation study was designed to screen patients for major toxicity in a large proportion of the pazopanib and bevacizumab patient-treated population. Based on binomial probabilities, in three patients (six, and nine patients respectively) cohort, the probability to observe one or more DLT, if that DLT occurred in at 
least $54 \%$ (32 and 23\% respectively) of the population, was $90 \%$. A descriptive analysis was performed to describe patient demographics and clinical characteristics, occurrence of adverse events (AE), incidence per CTCAE grade and dose level, and response rates. PFS was defined as the time from the date of first study drug administration until the date of first documented progression or death from any cause, and analyzed using the Kaplan-Meier method. Censoring was applied in the following situations: lost to follow-up and no event before cut-off (Oct 7th, 2013). Associations between dose, PK variables, and toxicity were established using Pearson correlation coefficients and compared using the two-tailed $t$ test. SAS version 9.3 was used for all statistical analyses.

\section{Results}

Patients

Between July 2010 and August 2012, 25 patients were enrolled including the six patients of the additional confirmatory cohort. Seven patients had mRCC (only one has not previously undergone a nephrectomy) whereas other patients had melanoma $(n=4)$, pancreatic cancer $(n=2)$, head and neck $(n=2)$ and cervix cancer $(n=2)$ (Table 1). The median (range) age was $62(41-79)$ and 14 (56\%) patients were males. Nine $(37.5 \%)$ patients had a history of hypertension but the blood pressure was adequately controlled at the time of inclusion. The median number (range) of previous treatments in patients with other tumors than mRCC was 3 (1-6). No patient had previously received VEGFR tyrosine kinase inhibitors. One patient with metastatic breast cancer had previously received bevacizumab in combination with paclitaxel.

\section{Treatment administration}

Nine patients were enrolled in the initial cohort and received $400 \mathrm{mg}$ pazopanib combined with $7.5 \mathrm{mg} / \mathrm{kg}$ bevacizumab (DL1), ten patients of the second cohort received $600 \mathrm{mg}$ pazopanib with $7.5 \mathrm{mg} / \mathrm{kg}$ bevacizumab (DL2) (Fig. 1). One patient was withdrawn after having received a non-authorized reduced dose. Since thrombotic microangiopathy (TMA) occurred in two patients in the second step at dose level 2, the DSMB recommended to include exclusively non-nephrectomized patients in the third step to limit the risk of an induced TMA. A confirmatory cohort of six patients received treatments at DL1. Patients received the treatment during a median (range) duration of 6 (1.9-52.4) weeks. Treatment discontinuation was decided because of progression for 12 patients, adverse events for 12 other patients and investigator's decision for one. The main reasons for discontinuation before the 24-week tumor assessment were disease progression $(n=7)$ or toxicity $(n=11)$. One patient with $\mathrm{mRCC}$ discontinued treatment since the resection of a single residual pancreatic metastasis was decided. Treatment-related adverse events led to pazopanib dose modifications in 11 of the 25 patients (eight dose interruptions and three dose reductions). Bevacizumab administration was delayed because of toxic effects in six patients, five at DL1 and one at DL2.

\section{Safety and MTD determination}

The dose escalation and DLT are listed in Table 2. No DLT was observed within the initial cohort (DL1) of nine patients. Ten patients were enrolled at DL2 i.e. $600 \mathrm{mg}$ pazopanib combined with $7.5 \mathrm{mg} / \mathrm{kg}$ bevacizumab, five DLT were observed. Two patients experienced a grade 3 hepatic cytolysis with ALT/AST elevation (ALT >6xULN and AST >3xULN; ALT >9xULN and AST $>7 x U L N$, respectively) associated with hyperbilirubinemia (total bilirubin $>1.7 x U L N$ and $>1.2 x U L N$, respectively). A pulmonary embolism occurred in one patient. Two patients developed clinical features consistent with a microangiopathic hemolytic anemia (MAHA) syndrome with proteinuria, hemolytic anemia, low haptoglobin, thrombocytopenia, and serum creatinine increase, 4 weeks after pazopanib initiation and 2 weeks after the first bevacizumab infusion. To note, one of these patients was previously nephrectomized for his $\mathrm{RCC}$ and had a creatinine level above normal at baseline (122 $\mu \mathrm{mol} / \mathrm{L}$ for a normal range upper value of $110 \mu \mathrm{mol} / \mathrm{L})$; both patients had a history of hypertension.

In the six non-nephrectomized patients enrolled in the confirmatory cohort at DL1, one patient with metastatic melanoma was not assessable for MTD of the combination because of an early grade 3 thrombocytopenia during the first fortnight of pazopanib administration, and before any bevacizumab infusion. Grade 3 ALT/AST elevations were observed in one patient. Two patients developed a MAHA syndrome (grade 3) with proteinuria, hematuria, renal impairment, and thrombocytopenia; a renal biopsy confirmed the diagnosis of thrombotic microangiopathy in both cases. One occurred 4 weeks after pazopanib initiation and 2 weeks after the first bevacizumab injection, the other 6 weeks after pazopanib initiation and 1 week after the second bevacizumab injection. Patients had no history of hypertension and a normal renal function at baseline.

Adverse events (any grade) are shown in Table 3. The most frequently reported adverse events included fatigue (52\%), hypertension (48\%), anorexia (44\%) and nausea (44\%). The most frequently reported grade 3 and 4 adverse events included TMA (16\%), thrombocytopenia (12\%), abdominal pain (8\%), thoracic musculoskeletal pain $(8 \%)$, hypertension (8\%) and proteinuria (8\%) (Table $4)$. The occurrence of grade 3-4 events was equally 
Table 1 Patient Demographics and Clinical Characteristics. Data are median (range) or $\mathrm{n}(\%)$ unless otherwise indicated

\begin{tabular}{|c|c|c|c|c|c|c|}
\hline \multirow{3}{*}{$\begin{array}{l}\text { Characteristics } \\
\text { Median Age, years (min-max) } \\
\text { Male }\end{array}$} & \multicolumn{2}{|c|}{$\begin{array}{l}\text { Renal cell carcinoma } \\
N=7(28.0 \%)\end{array}$} & \multicolumn{2}{|c|}{$\begin{array}{l}\text { Other tumor types } \\
N=18(72.0 \%)\end{array}$} & \multicolumn{2}{|c|}{$\begin{array}{l}\text { Patients } \\
N=25\end{array}$} \\
\hline & \multicolumn{2}{|c|}{$53.10(43.80-71.20)$} & \multicolumn{2}{|c|}{$62.55(41.00-78.60)$} & \multicolumn{2}{|c|}{$61.90(41.00-78.60)$} \\
\hline & 5 & $(71.4)$ & 9 & $(50.0)$ & 14 & $(56.0)$ \\
\hline History of hypertension & 3 & $(42.9)$ & 6 & $(33.3)$ & 9 & $(36.0)$ \\
\hline Nephrectomy & 6 & $(85.7)$ & 1 & $(5.0)$ & 7 & $(87.5)$ \\
\hline \multicolumn{7}{|l|}{ Localization } \\
\hline Cervix cancer & 0 & - & 2 & $(11.1)$ & 2 & (8.1) \\
\hline Colorectal cancer & 0 & - & 1 & $(5.6)$ & 1 & (5.6) \\
\hline Melanoma & 0 & - & 4 & $(22.2)$ & 4 & (16.0) \\
\hline Pancreatic cancer & 0 & - & 2 & $(11.1)$ & 2 & $(8.1)$ \\
\hline Breast cancer & 0 & - & 1 & $(5.6)$ & 1 & (5.6) \\
\hline Adrenocortical carcinoma & 0 & - & 1 & $(5.6)$ & 1 & (5.6) \\
\hline Seminoma & 0 & - & 1 & $(5.6)$ & 1 & (5.6) \\
\hline Lung cancer & 0 & - & 1 & $(5.6)$ & 1 & $(5.6)$ \\
\hline Other (head and neck, thyroid, bladder, mesothelioma) & 0 & - & 5 & $(27.8)$ & 5 & $(25.0)$ \\
\hline M0 at diagnosis & 5 & $(71.4)$ & 13 & $(72.2)$ & 18 & $(72.0)$ \\
\hline \multicolumn{7}{|l|}{ Time between diagnosis and first metastases } \\
\hline Mean (std) & \multicolumn{2}{|c|}{$11.86(15-27)$} & \multicolumn{2}{|c|}{$21.73(23-56)$} & \multicolumn{2}{|c|}{$18.85(21-64)$} \\
\hline Median (min-max) & \multicolumn{2}{|c|}{$12.88(-1.28-43.20)$} & \multicolumn{2}{|c|}{$16.29(-0.39-80.06)$} & \multicolumn{2}{|c|}{$13.14(-1.28-80.06)$} \\
\hline Missing & \multicolumn{2}{|l|}{0} & \multicolumn{2}{|l|}{1} & \multicolumn{2}{|l|}{1} \\
\hline \multicolumn{7}{|l|}{ Time between diagnosis and first metastases } \\
\hline$\leq 12$ months & 3 & $(42.9)$ & 7 & $(41.2)$ & 10 & $(41.7)$ \\
\hline$>12$ months & 4 & $(57.1)$ & 10 & $(58.8)$ & 14 & $(58.3)$ \\
\hline Missing & 0 & & 1 & & 1 & \\
\hline \multicolumn{7}{|l|}{ Number of metastatic sites } \\
\hline 1 & 5 & $(71.4)$ & 12 & $(70.6)$ & 17 & $(70.8)$ \\
\hline$>1$ & 2 & $(28.6)$ & 5 & $(29.4)$ & 7 & $(29.2)$ \\
\hline Missing & \multicolumn{2}{|l|}{0} & \multicolumn{2}{|l|}{1} & \multicolumn{2}{|l|}{1} \\
\hline Median (min-max) & \multicolumn{2}{|c|}{$1(1-1)$} & $3(1$ & & $3(1$ & \\
\hline Number of prior therapy & & & & & & \\
\hline Chemotherapy & 1 & $(14.3)$ & 18 & $(100.0)$ & 19 & $(76.0)$ \\
\hline Median number of previous chemotherapy (min-max) & 1( & & $3(1$ & & $3(1$ & \\
\hline Bevacizumab & 0 & $(0.0)$ & 1 & $(5.6)$ & 1 & $(5.3)$ \\
\hline Radiotherapy & 3 & $(42.9)$ & 13 & $(72.2)$ & 16 & $(64.0)$ \\
\hline Hemoglobin & & & & & & \\
\hline$<115 \mathrm{~g} / \mathrm{L}(\mathrm{F}),<130 \mathrm{~g} / \mathrm{L}(\mathrm{M})$ & 1 & $(14.3)$ & 7 & $(38.9)$ & 8 & $(32.0)$ \\
\hline$\geq 115 \mathrm{~g} / \mathrm{L}(\mathrm{F}), \geq 130 \mathrm{~g} / \mathrm{L}(\mathrm{M})$ & 6 & $(85.7)$ & 11 & $(61.1)$ & 17 & $(68.0)$ \\
\hline Serum creatinine $(\mu \mathrm{mol} / \mathrm{L})$ & & & & & & \\
\hline Median (min-max) & 97. & 27.0) & 79.5 & 27.0) & 84. & 27.0) \\
\hline Missing & 1 & & 0 & & 1 & \\
\hline AST (UI/L) & & & & & & \\
\hline Median (min-max) & 17. & & 33.0 & 4.0) & 24. & \\
\hline Missing & 1 & & 0 & & 1 & \\
\hline
\end{tabular}


Table 1 Patient Demographics and Clinical Characteristics. Data are median (range) or $\mathrm{n}(\%)$ unless otherwise indicated (Continued)

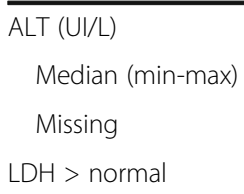

represented in the first $(n=16)$ and in the second dose level $(n=14)$.

The DL1 (400 mg pazopanib-7.5 $\mathrm{mg} / \mathrm{kg}$ bevacizumab) was defined as the MTD since no DLT was observed in the nine first patients treated at DL1 but three DLTs occurred in the six additional patients.

\section{Pharmacokinetics}

The mean (range) plasma concentration (AUC) with 400 and $600 \mathrm{mg}$ pazopanib administration were respectively 283 (139-427) $(n=15)$, and 494 (227-761) $\mu \mathrm{g} \cdot \mathrm{h} / \mathrm{mL}$ $(n=10)$ at Day 1 , and 738 (487-989) and 1071 (6781464) $\mu \mathrm{g} . \mathrm{h} / \mathrm{mL}$ at Day 15 , with $37 \%$ of inter-individual variability in apparent clearance. These values were significantly higher than those previously described in the initial phase 1 trial with pazopanib as monotherapy [37]. However, they were not influenced by bevacizumab infusion since pazopanib trough plasma concentrations were not significantly higher $24 \mathrm{~h}$ after bevacizumab infusion than before infusion (at D15). The detailed results were previously published [36].

\section{Efficacy}

As of the cutoff data for data analysis (Oct 7th, 2013), the median (range) follow-up was 11.4 months (1.825.8). Twenty-two patients were evaluable for response to treatment. To note, two patients stopped prematurely the experimental treatment for toxicity after a treatment period of 4 and 5 weeks respectively, and one patient never received bevacizumab. The best overall response observed was partial response (PR) in five (22.7\%) patients (three at DL1 and two at DL2; responses occurring in $\mathrm{mRCC}$, lung cancer, cervix cancer $(n=2)$, and seminoma patients), stable disease (SD) in 11 (50\%) patients (eight at DL1 and three at DL2; five patients with mRCC and six with other tumors), and progressive disease (PD) in six $(27.3 \%)$ patients (three at each DL; six patients with other tumors than mRCC). The 24-week progression-free rate was 33.3\% (95\% CI, 15.63-55.32\%) in the whole study cohort, with a median PFS of 18 (95\% CI, 15-30) weeks (Fig. 2). No difference in PFS was observed in patients at DL1 and those at DL2 (data not shown). Median PFS were 23.3 weeks (95\% CI, 15.7-31.4) and 17.1 weeks (95\% CI, 8.1-26.7) in patients with $\mathrm{mRCC}$ and other tumor types, respectively.

\section{Discussion}

The combination of the VEGF-directed monoclonal antibody bevacizumab with a tyrosine kinase inhibitor directed against VEGF receptors has already been investigated [28]. These combination regimens were difficult to manage since increased toxicities have been described, and some of them were even considered as not feasible despite promising efficacy. The more recently registered TKI pazopanib, appeared to induce fewer side effects than other previous VEGFR TKIs [8, 38]. Most patients with mRCC also preferred pazopanib to sunitinib [39]. The combination of pazopanib and bevacizumab appeared feasible and a promising efficacy was expected. This trial is the first to report this combination in patients with different solid tumor including $\mathrm{mRCC}$ patients.

The MTD was $400 \mathrm{mg}$ pazopanib and $7.5 \mathrm{mg}$ bevacizumab, defined as the initial DL combination to investigate in this trial. These doses are equivalent to one half of pazopanib and three-quarters of bevacizumab doses recommended when administrated as monotherapy. AST or ALT increases to up to a grade 3 toxicity level

Table 2 DLTS according to dose levels

\begin{tabular}{|c|c|c|c|c|}
\hline Dose level & $\begin{array}{l}\text { Number of Assessable } \\
\text { patients }\end{array}$ & $\begin{array}{l}\text { Bevacizumab } \\
\text { (Q2W) }\end{array}$ & $\begin{array}{l}\text { Pazopanib } \\
\text { (Q.D) }\end{array}$ & Number of DLT \\
\hline DL1 & 9 & $7.5 \mathrm{mg} / \mathrm{kg}$ & $400 \mathrm{mg}$ & No DLT \\
\hline \multirow[t]{2}{*}{ DL1 Confirmatory Cohort } & 6 & & & 3 DLT:- 2 grade $3 M A H A^{b}$ \\
\hline & & & & - 1 grade 3 ALT/AST \\
\hline \multirow[t]{3}{*}{ DL2 } & $10^{\mathrm{a}}$ & $7.5 \mathrm{mg} / \mathrm{kg}$ & 600 mg & 5 DLT:- 2 grade 3 ALT/AST ${ }^{c}$ \\
\hline & & & & - 1 grade 3 pulmonary embolism ${ }^{c}$ \\
\hline & & & & - 2 grade $3 M^{\prime} H A^{c}$ \\
\hline
\end{tabular}

\footnotetext{
${ }^{\mathrm{a}} 1$ patient dropped out for non-authorized dose reduction at week 5

${ }^{b}$ MAHA: Microangiopathic \& hemolytic anemia
}

coccurred in one nephrectomized patient 
Table 3 Adverse events (all grades, occurring in $>10 \%$ of patients). Total number of patients $N=25$

\begin{tabular}{|c|c|c|c|c|c|c|}
\hline & \multicolumn{6}{|c|}{ Grade } \\
\hline & \multirow{2}{*}{$\begin{array}{l}1 \\
N\end{array}$} & \multirow{2}{*}{$\begin{array}{l}2 \\
N\end{array}$} & \multirow{2}{*}{$\begin{array}{l}3 \\
N\end{array}$} & \multirow{2}{*}{$\begin{array}{l}4 \\
N\end{array}$} & \multicolumn{2}{|l|}{ All } \\
\hline & & & & & $\bar{N}$ & $\%$ \\
\hline Fatigue & 6 & 6 & 1 & 0 & 13 & 52.0 \\
\hline Hypertension & 4 & 6 & 2 & 0 & 12 & 48.0 \\
\hline Anorexia & 8 & 3 & 0 & 0 & 11 & 44.0 \\
\hline Nausea & 11 & 0 & 0 & 0 & 11 & 44.0 \\
\hline Asthenia & 6 & 4 & 0 & 0 & 10 & 40.0 \\
\hline Diarrhea & 8 & 1 & 1 & 0 & 10 & 40.0 \\
\hline Dysphonia & 10 & 0 & 0 & 0 & 10 & 40.0 \\
\hline Vomiting & 7 & 2 & 1 & 0 & 10 & 40.0 \\
\hline Thrombocytopenia & 3 & 2 & 3 & 0 & 8 & 32.0 \\
\hline Headache & 6 & 0 & 0 & 0 & 6 & 24.0 \\
\hline Abdominal pain & 2 & 2 & 2 & 0 & 6 & 24.0 \\
\hline Dysgeusia & 4 & 2 & 0 & 0 & 6 & 24.0 \\
\hline Myalgia & 5 & 1 & 0 & 0 & 6 & 24.0 \\
\hline Neck pain & 4 & 1 & 0 & 0 & 5 & 20.0 \\
\hline Hypothyroidism & 3 & 2 & 0 & 0 & 5 & 20.0 \\
\hline Proteinuria & 0 & 3 & 2 & 0 & 5 & 20.0 \\
\hline Dry skin & 4 & 1 & 0 & 0 & 5 & 20.0 \\
\hline Arthralgia & 3 & 1 & 0 & 0 & 4 & 16.0 \\
\hline Elevated bilirubin & 0 & 4 & 0 & 0 & 4 & 16.0 \\
\hline Muscular contractures & 4 & 0 & 0 & 0 & 4 & 16.0 \\
\hline Hair modified color & 4 & 0 & 0 & 0 & 4 & 16.0 \\
\hline Epistaxis & 4 & 0 & 0 & 0 & 4 & 16.0 \\
\hline Hemorrhoids & 3 & 1 & 0 & 0 & 4 & 16.0 \\
\hline Microangiopathy & 0 & 0 & 4 & 0 & 4 & 16.0 \\
\hline Paresthesia & 4 & 0 & 0 & 0 & 4 & 16.0 \\
\hline Stomatitis & 2 & 2 & 0 & 0 & 4 & 16.0 \\
\hline Hand \& foot syndrome & 3 & 0 & 1 & 0 & 4 & 16.0 \\
\hline Mucositis & 3 & 1 & 0 & 0 & 4 & 16.0 \\
\hline Elevated AST & 2 & 1 & 0 & 0 & 3 & 12.0 \\
\hline Back pain & 2 & 1 & 0 & 0 & 3 & 12.0 \\
\hline Musculoskeletal pain & 2 & 1 & 0 & 0 & 3 & 12.0 \\
\hline Thoracic musculoskeletal pain & 0 & 1 & 2 & 0 & 3 & 12.0 \\
\hline Dyspnea & 3 & 0 & 0 & 0 & 3 & 12.0 \\
\hline Urinary tract infection & 0 & 3 & 0 & 0 & 3 & 12.0 \\
\hline Neutropenia & 0 & 3 & 0 & 0 & 3 & 12.0 \\
\hline
\end{tabular}

were considered as a DLT in three patients. This severe hepatotoxicity was already described in trials investigating pazopanib as monotherapy $[8,38,40,41]$. This VEGFR TKI appears to commonly induce some hepatotoxicity. However, the rate of hepatic toxicity was notably higher in the large pazopanib phase III trial $(N=557)$, than that observed with the combined treatment [38]. Hepatic toxicity might therefore not be linked to the combination under investigation. On the opposite, the occurrence of a microangiopathic hemolytic anemia (MAHA), initially reported with bevacizumab but also observed with sunitinib, might be favored by the combination of both agents targeting the VEGF pathway [42-44]. Four patients with MAHA syndrome were observed in our series; two occurred at DL2 in patients with a history of hypertension, one of them previously underwent a nephrectomy and had an increased creatinine level before receiving the treatment. MAHA syndromes were also observed in two patients within the non-nephrectomized additional cohort of patients treated at DL1. Both occurred in patients with no history of hypertension and with previously normal renal function. Our results demonstrate that this vasculo-renal impairment can be induced in patients without any vascular or renal pre-existing risk. Thrombotic microangiopathy (TMA), as the initial phenomenon in the development of a MAHA syndrome, has been reported by several authors investigating the combination of sunitinib and bevacizumab [25, 28, 45]. On the contrary, another registered TKI directed against VEGFR, sorafenib, combined with bevacizumab did not mention any occurrence of MAHA syndrome nor TMA [14, 16, 19]. Pazopanib combined with bevacizumab might damage the renal nephron, with a rapid onset of a microangiopathy closed to that reported in the combination of bevacizumab with sunitinib [28]. In addition, our series confirmed that this microangiopathic effect does not only occur in patients suffering from renal tumors.

To note, no significant change in pazopanib PK was noticed following bevacizumab administration, especially in patients who experienced severe adverse events [36]. Moreover, the mean daily AUC at Day 15 (i.e., $1071 \pm 398 \mu \mathrm{g} \cdot \mathrm{h} / \mathrm{mL}$ ) at the maximum dose tested (600 mg) in combination with bevacizumab was higher in this trial than that determined in the first-in-man phase 1 study with $800 \mathrm{mg}$ pazopanib once-daily administration as monotherapy (i.e. $743 \pm 76 \mu$ g.h $/ \mathrm{mL}, n=8$ ) [37]. This could be related to a different patient selection and may explain the poor tolerance we observed, imposing $400 \mathrm{mg}$ pazopanib as the maximum tolerated dose in the combination with bevacizumab.

Beside these dose limiting toxicities, the type and frequency of other adverse events were similar to those observed with pazopanib as monotherapy in large randomized trial [38].

Even if $22 \%$ patients achieved a partial response, the response rate in the six mRCC patients, with one responding patient only, was not promising despite the administration of this combination in first-line setting. Interestingly, several objective responses were observed in other heavily pretreated tumors. If bevacizumab is 
Table 4 Grade 3/4 adverse events according to dose level and nephrectomy

\begin{tabular}{|c|c|c|c|c|c|c|c|c|c|c|}
\hline & \multicolumn{4}{|l|}{ Dose level 1} & \multicolumn{4}{|l|}{ Dose level 2} & \multirow{2}{*}{\multicolumn{2}{|c|}{$\begin{array}{l}\text { All } \\
N=25\end{array}$}} \\
\hline & \multirow{2}{*}{$\begin{array}{l}\text { Nephrec-tomized } \\
N=4 \\
N\end{array}$} & \multirow{2}{*}{$\begin{array}{l}\text { Non nephrec-tomized } \\
N=11 \\
N\end{array}$} & \multicolumn{2}{|c|}{$\begin{array}{l}\text { All } \\
N=15\end{array}$} & \multirow{2}{*}{$\begin{array}{l}\text { Nephrec-tomized } \\
N=3 \\
N\end{array}$} & \multirow{2}{*}{$\begin{array}{l}\text { Non nephrec-tomized } \\
N=7 \\
N\end{array}$} & \multicolumn{2}{|c|}{$\begin{array}{l}\text { All } \\
N=10\end{array}$} & & \\
\hline & & & $\mathrm{N}$ & $\%$ & & & $\mathrm{~N}$ & $\%$ & $\mathrm{~N}$ & $\%$ \\
\hline Thrombotic microangiopathy (TMA) & 0 & 2 & 2 & 13.3 & 1 & 1 & 2 & 20.0 & 4 & 16.0 \\
\hline Thrombocytopenia & 0 & 2 & 2 & 13.3 & 0 & 1 & 1 & 10.0 & 3 & 12.0 \\
\hline Elevated ALT and/or AST & 0 & 1 & 1 & 6.7 & 1 & 1 & 2 & 20.0 & 3 & 12.0 \\
\hline Abdominal pain & 0 & 1 & 1 & 6.7 & 0 & 1 & 1 & 10.0 & 2 & 8.0 \\
\hline Thoracic musculoskeletal pain & 0 & 2 & 2 & 13.3 & 0 & 0 & 0 & 0.0 & 2 & 8.0 \\
\hline Hypertension & 0 & 0 & 0 & 0.0 & 1 & 1 & 2 & 20.0 & 2 & 8.0 \\
\hline Proteinuria & 1 & 0 & 1 & 6.7 & 0 & 1 & 1 & 10.0 & 2 & 8.0 \\
\hline Perianal abscess & 1 & 0 & 1 & 6.7 & 0 & 0 & 0 & 0.0 & 1 & 4.0 \\
\hline Seizure & 0 & 1 & 1 & 6.7 & 0 & 0 & 0 & 0.0 & 1 & 4.0 \\
\hline Diarrhea & 0 & 0 & 0 & 0.0 & 0 & 1 & 1 & 10.0 & 1 & 4.0 \\
\hline Confusion $^{a}$ & 0 & 1 & 1 & 6.7 & 0 & 0 & 0 & 0.0 & 1 & 4.0 \\
\hline Fatigue & 0 & 1 & 1 & 6.7 & 0 & 0 & 0 & 0.0 & 1 & 4.0 \\
\hline Hypernatremia & 0 & 0 & 0 & 0.0 & 1 & 0 & 1 & 10.0 & 1 & 4.0 \\
\hline Post-surgery bleeding & 0 & 0 & 0 & 0.0 & 1 & 0 & 1 & 10.0 & 1 & 4.0 \\
\hline Lipase increase & 0 & 0 & 0 & 0.0 & 1 & 0 & 1 & 10.0 & 1 & 4.0 \\
\hline Pyelonephritis & 0 & 1 & 1 & 6.7 & 0 & 0 & 0 & 0.0 & 1 & 4.0 \\
\hline Hand \& foot syndrome & 1 & 0 & 1 & 6.7 & 0 & 0 & 0 & 0.0 & 1 & 4.0 \\
\hline Venous thrombosis & 0 & 0 & 0 & 0.0 & 1 & 0 & 1 & 10.0 & 1 & 4.0 \\
\hline Vomiting & 0 & 1 & 1 & 6.7 & 0 & 0 & 0 & 0.0 & 1 & 4.0 \\
\hline
\end{tabular}

${ }^{\mathrm{a}}$ Grade 4 adverse event

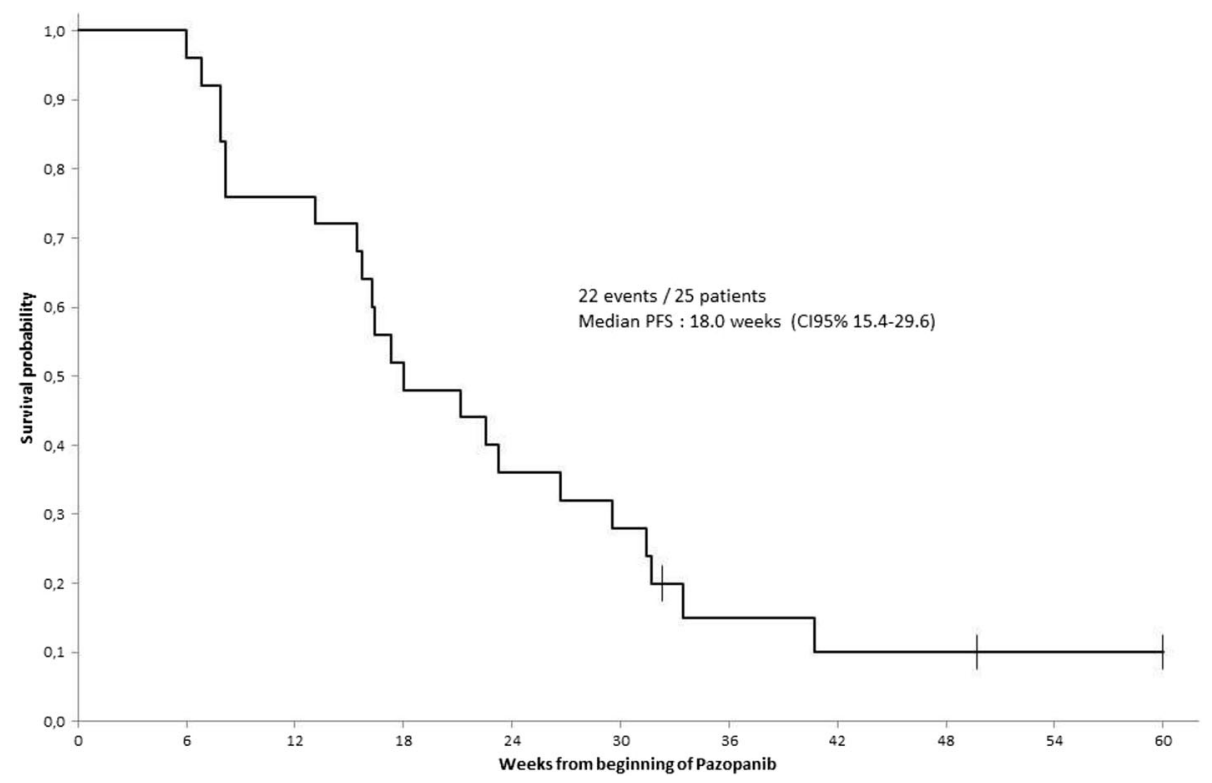

Fig. 2 Progression-free Survival 
already part of the treatment strategy used in cervix and lung carcinomas $[3,46]$, a significant tumor reduction in a patient with a seminoma was more surprising.

\section{Conclusions}

The combination of pazopanib and bevacizumab displays significant toxicity. This combination required the use of reduced doses compared to their respective monotherapy administration. A microangiopathy was observed in some patients without any specific preexisting vascular or renal conditions. The safety issues, together with a rather disappointing efficacy rate, preclude the further development of this combination.

\begin{abstract}
Abbreviations
AE: Adverse event; ALT: Alanine aminotransferase; APPT: Activated partial thromboplastin time; AST: Aspartate aminotransferase; CTCAE: National Cancer Institute Common Terminology Criteria for Adverse Events; DL: Dose levels; DLT: Dose limiting toxicities; DSMB: Independent Data and Safety Monitoring Committee; ECOG-PS: Eastern Cooperative Oncology Group performance status; MAHA: Microangiopathic hemolytic anemia; mRCC: Metastatic renal cell carcinoma; MTD: Maximum tolerated dose; PDGFR: Platelet-derived-growth-factor receptor; PK: Pharmacokinetics; PT: Prothrombine time; TKI: Tyrosine kinase inhibitors; TMA: Thrombotic microangiopathy; ULN: Upper limit of normal [ULN]; VEGF: Vascular endothelial growth factor; VEGFR: VEGF receptors
\end{abstract}

\section{Acknowledgements}

The trial was supported by GlaxoSmithKline and Roche. The authors thank the participating patients, staff at each study site, the independent data and safety monitoring committee members. The authors thank Sophie Darnis (Centre Léon Bérard) for medical editorial assistance with this manuscript.

\section{Funding}

The Centre Léon Bérard as sponsor was responsible for trial conception and coordination, data analysis and publication writing. Study drugs were graciously provided. Glaxo Smith Kline (Marly-le-Roi, France) provided pazopanib (Votrient $\left.{ }^{\oplus}\right)$; Roche (Boulogne-Billancourt, France) provided bevacizumab (Avastin $\left.{ }^{\oplus}\right)$. The study was funded by Glaxo Smith Kline. The funder had no role in study design, data collection, data analysis, data interpretation, or writing of the report.

\section{Availability of data and materials}

The datasets generated or analyzed during the study are available from the corresponding author on reasonable request.

\section{Authors' contributions}

$S N, D P, E B$, and $B E$ contributed to conception and design of the trial. SN, RB, $A H, E C, H B, P C, S M, J-C S$, and BE contributed to acquisition of data or analysis and interpretation. DP did the statistical analysis and contributed together with $\mathrm{SN}, \mathrm{SM}, \mathrm{EC}$, and EB to data analysis and interpretation. SN, EB and DP supervised the study. SN and EB drafted the manuscript. All authors critically revised the manuscript for important intellectual content and approved the final version to be published. All authors agreed to be accountable for all aspects of the work in ensuring that questions related to the accuracy or integrity in any part of the work are appropriately investigated and resolved.

\section{Ethics approval and consent to participate}

The trial received local approval of the Ethic Committee of Lyon Sud-Est IV ( $\left.n^{\circ} 10 / 008\right)$. Initial approval was obtained on 2010, Feb 1st. All patients provided written informed consent before enrolment.

The study was retrospectively registered on ClinicalTrials.gov, number NCT01202032 on 2010, Sept 14th. The date of enrolment of the first patient in the protocol was 2010, July 2 d.

\section{Consent for publication}

Not applicable.

\section{Competing interests}

Reagents and funding were received from both Glaxo Smith Kline and Roche. S. Négrier received honoraria from Pfizer, Novartis, EUSA Pharma, IPSEN and Bristol-Meyer Squibb. D. Pérol received honoraria from Novartis, Lilly, Pierre Fabre, is a consultant/advisory board member for Celgene, Janssen and Roche, and received personal compensation for travel/accommodations from Roche. $\mathrm{H}$. Boyle received honoraria for presentations and personal compensation for travel/accommodations from Pfizer, Sanofi, Janssen, Novartis, Amgen, and Astellas. P. Cassier received research support from Roche/Genentech, and honoraria from Roche. J.C. Soria declares personal compensation for travel/ accommodations, and personal consultancy fees (<10,000 USD) from Roche. B. Escudier received honoraria from Pfizer, Novartis, Bristol-Myers Squibb Roche, and Exelixis. No potential competing interest were disclosed by the other authors.

\section{Publisher's Note}

Springer Nature remains neutral with regard to jurisdictional claims in published maps and institutional affiliations.

\section{Author details}

'University Lyon, Université Claude Bernard Lyon 1, Centre Léon Bérard, Lyon, France. ${ }^{2}$ Clinical Research and Innovation Department, Centre Léon Bérard, F-69373, Lyon, Cedex 08, France. ${ }^{3}$ DITEP -Département d'Innovation Thérapeutiques et Essais Précoces, Institut Gustave Roussy, 94805 Villejuif Cedex, France. ${ }^{4}$ Institut Claudius Regaud, Inserm UMR1037 CRCT, Université Paul-Sabatier, 20/24 rue du Pont Saint-Pierre, 31052 Toulouse, France. ${ }^{5}$ Medical Oncology Department, Centre Léon Bérard, F-69373, Lyon, Cedex 08, France. ${ }^{6}$ University of Paris Sud, Orsay, Institut Gustave Roussy, 94805 Villejuif Cedex, France. 'Department of Medical Oncology, Institut Gustave Roussy, 114, rue Edouard-Vaillant, 94805 Villejuif Cedex, France.

Received: 21 March 2017 Accepted: 1 August 2017

Published online: 15 August 2017

\section{References}

1. Yang JC, Haworth L, Sherry RM, Hwu P, Schwartzentruber DJ, Topalian SL, et al. A randomized trial of bevacizumab, an anti-vascular endothelial growth factor antibody, for metastatic renal cancer. N Engl J Med. 2003;349:427-34.

2. Hurwitz H, Fehrenbacher L, Novotny W, Cartwright T, Hainsworth J, Heim W, et al. Bevacizumab plus irinotecan, fluorouracil, and leucovorin for metastatic colorectal cancer. N Engl J Med. 2004;350:2335-42.

3. Sandler A, Gray R, Perry MC, Brahmer J, Schiller JH, Dowlati A, et al. Paclitaxel-carboplatin alone or with bevacizumab for non-small-cell lung cancer. N Engl J Med. 2006;355:2542-50.

4. Miller K, Wang M, Gralow J, Dickler M, Cobleigh M, Perez EA, et al. Paclitaxel plus bevacizumab versus paclitaxel alone for metastatic breast cancer. $N$ Engl J Med. 2007:357:2666-76.

5. Llovet JM, Ricci S, Mazzaferro V, Hilgard P, Gane E, Blanc JF, et al. Sorafenib in advanced hepatocellular carcinoma. N Engl J Med. 2008;359:378-90.

6. Motzer RJ, Hutson TE, Tomczak P, Michaelson MD, Bukowski RM, Rixe O, et al. Sunitinib versus interferon alfa in metastatic renal-cell carcinoma. N Engl J Med. 2007;356:115-24.

7. Escudier B, Pluzanska A, Koralewski P, Ravaud A, Bracarda S, Szczylik C, et al. Bevacizumab plus interferon alfa-2a for treatment of metastatic renal cell carcinoma: a randomised, double-blind phase III trial. Lancet. 2007;370: 2103-11.

8. Sternberg CN, Davis ID, Mardiak J, Szczylik C, Lee E, Wagstaff J, et al. Pazopanib in locally advanced or metastatic renal cell carcinoma: results of a randomized phase III trial. J Clin Oncol. 2010;28:1061-8.

9. Hudes G, Carducci M, Tomczak P, Dutcher J, Figlin R, Kapoor A, et al. Temsirolimus, interferon alfa, or both for advanced renal-cell carcinoma. N Engl J Med. 2007;356:2271-81.

10. Escudier B, Eisen T, Stadler WM, Szczylik C, Oudard S, Siebels M, et al. Sorafenib in advanced clear-cell renal-cell carcinoma. N Engl J Med. 2007; 356:125-34.

11. Rini BI, Escudier B, Tomczak P, Kaprin A, Szczylik C, Hutson TE, et al. Comparative effectiveness of axitinib versus sorafenib in advanced renal cell carcinoma (AXIS): a randomised phase 3 trial. Lancet. 2011;378:1931-9.

12. Choueiri TK, Escudier B, Powles T, Tannir NM, Mainwaring PN, Rini BI, et al. Cabozantinib versus everolimus in advanced renal cell carcinoma (METEOR): 
final results from a randomised, open-label, phase 3 trial. Lancet Oncol. 2016:17:917-27.

13. Motzer RJ, Hutson TE, Glen H, Michaelson MD, Molina A, Eisen T, et al. Lenvatinib, everolimus, and the combination in patients with metastatic renal cell carcinoma: a randomised, phase 2, open-label, multicentre trial. Lancet Oncol. 2015;16:1473-82.

14. Azad NS, Posadas EM, Kwitkowski VE, Steinberg SM, Jain L, Annunziata CM, et al. Combination targeted therapy with sorafenib and bevacizumab results in enhanced toxicity and antitumor activity. J Clin Oncol. 2008;26:3709-14.

15. Negrier S, Gravis G, Perol D, Chevreau C, Delva R, Bay JO, et al. Temsirolimus and bevacizumab, or sunitinib, or interferon alfa and bevacizumab for patients with advanced renal cell carcinoma (TORAVA): a randomised phase 2 trial. Lancet Oncol. 2011:12:673-80.

16. Castellano D, Capdevila J, Sastre J, Alonso V, Llanos M, Garcia-Carbonero R, et al. Sorafenib and bevacizumab combination targeted therapy in advanced neuroendocrine tumour: a phase II study of Spanish Neuroendocrine tumour group (GETNE0801). Eur J Cancer. 2013:49:3780-7.

17. Mina LA, Yu M, Johnson C, Burkhardt C, Miller KD, Zon R. A phase II study of combined VEGF inhibitor (bevacizumab+sorafenib) in patients with metastatic breast cancer: Hoosier oncology group study BRE06-109. Investig New Drugs. 2013;31:1307-10

18. Mahalingam D, Malik L, Beeram M, Rodon J, Sankhala K, Mita A, et al. Phase II study evaluating the efficacy, safety, and pharmacodynamic correlative study of dual antiangiogenic inhibition using bevacizumab in combination with sorafenib in patients with advanced malignant melanoma. Cancer Chemother Pharmacol. 2014;74:77-84.

19. Galanis E, Anderson SK, Lafky JM, Uhm JH, Giannini C, Kumar SK, et al. Phase II study of bevacizumab in combination with sorafenib in recurrent glioblastoma (N0776): a north central cancer treatment group trial. Clin Cancer Res. 2013:19:4816-23.

20. Buti S, Bersanelli M. Combination therapy in kidney cancer: the next revolution? Lancet Oncol. 2015;16:1441-2.

21. Hegde PS, Jubb AM, Chen D, Li NF, Meng YG, Bernaards C, et al. Predictive impact of circulating vascular endothelial growth factor in four phase III trials evaluating bevacizumab. Clin Cancer Res. 2013;19:929-37.

22. Ljungberg B, Jacobsen J, Haggstrom-Rudolfssson S, Rasmuson T, Lindh G, Grankvist K. Tumour vascular endothelial growth factor (VEGF) mRNA in relation to serum VEGF protein levels and tumour progression in human renal cell carcinoma. Urol Res. 2003;31:335-40.

23. Negrier S, Perol D, Menetrier-Caux C, Escudier B, Pallardy M, Ravaud A, et al. Interleukin-6, interleukin-10, and vascular endothelial growth factor in metastatic renal cell carcinoma: prognostic value of interleukin-6-from the Groupe Francais d'Immunotherapie. J Clin Oncol. 2004;22:2371-8.

24. Choueiri TK, Motzer RJ. Systemic therapy for metastatic renal-cell carcinoma. N Engl J Med. 2017:376:354-66.

25. Feldman DR, Baum MS, Ginsberg MS, Hassoun H, Flombaum CD, Velasco S, et al. Phase I trial of bevacizumab plus escalated doses of sunitinib in patients with metastatic renal cell carcinoma. J Clin Oncol. 2009;27:1432-9.

26. Rini BI, Garcia JA, Cooney MM, Elson P, Tyler A, Beatty K, et al. A phase I study of sunitinib plus bevacizumab in advanced solid tumors. Clin Cancer Res. 2009;15:6277-83.

27. Moreno G. V, Basu B, Molife LR, Kaye SB: combining antiangiogenics to overcome resistance: rationale and clinical experience. Clin Cancer Res. 2012;18:3750-61

28. Mittal K, Koon H, Elson P, Triozzi P, Dowlati A, Chen H, et al. Dual VEGF/ VEGFR inhibition in advanced solid malignancies: clinical effects and pharmacodynamic biomarkers. Cancer Biol Ther. 2014;15:975-81.

29. Hutson TE, Davis ID, Machiels JP, De Souza PL, Rottey S, Hong BF, et al. Efficacy and safety of pazopanib in patients with metastatic renal cell carcinoma. J Clin Oncol. 2010;28:475-80.

30. Rini BI, Halabi S, Rosenberg JE, Stadler WM, Vaena DA, Ou SS, et al. Bevacizumab plus interferon alfa compared with interferon alfa monotherapy in patients with metastatic renal cell carcinoma: CALGB 90206. J Clin Oncol. 2008:26:5422-8.

31. Bukowski RM, Kabbinavar FF, Figlin RA, Flaherty K, Srinivas S, Vaishampayan $U$, et al. Randomized phase II study of erlotinib combined with bevacizumab compared with bevacizumab alone in metastatic renal cell cancer. J Clin Oncol. 2007;25:4536-41.

32. Flaherty KT, Manola JB, Pins M, McDermott DF, Atkins MB, Dutcher JJ, et al. BEST: a randomized phase II study of vascular endothelial growth factor, RAF Kinase, and mammalian target of Rapamycin combination targeted therapy with Bevacizumab, Sorafenib, and Temsirolimus in advanced renal cell carcinoma-a trial of the ECOG-ACRIN cancer research group (E2804). J Clin Oncol. 2015;33:2384-91.

33. Johnson DH, Fehrenbacher L, Novotny WF, Herbst RS, Nemunaitis JJ, Jablons DM, et al. Randomized phase II trial comparing bevacizumab plus carboplatin and paclitaxel with carboplatin and paclitaxel alone in previously untreated locally advanced or metastatic non-small-cell lung cancer. J Clin Oncol. 2004:22:2184-91.

34. Socinski MA, Scappaticci FA, Samant M, Kolb MM, Kozloff MF. Safety and efficacy of combining sunitinib with bevacizumab + paclitaxel/carboplatin in non-small cell lung cancer. J Thorac Oncol. 2010;5:354-60.

35. Eisenhauer EA, Therasse P, Bogaerts J, Schwartz LH, Sargent D, Ford R, et al. New response evaluation criteria in solid tumours: revised RECIST guideline (version 1.1). Eur J Cancer. 2009:45:228-47.

36. Imbs DC, Negrier S, Cassier P, Hollebecque A, Varga A, Blanc E, et al. Pharmacokinetics of pazopanib administered in combination with bevacizumab. Cancer Chemother Pharmacol. 2014:73:1189-96.

37. Hurwitz HI, Dowlati A, Saini S, Savage S, Suttle AB, Gibson DM, et al. Phase I trial of pazopanib in patients with advanced cancer. Clin Cancer Res. 2009;15: $4220-7$.

38. Motzer RJ, Hutson TE, Cella D, Reeves J, Hawkins R, Guo J, et al. Pazopanib versus sunitinib in metastatic renal-cell carcinoma. N Engl J Med. 2013;369: $722-31$.

39. Escudier B, Porta C, Bono P, Powles T, Eisen T, Sternberg CN, et al. Randomized, controlled, double-blind, cross-over trial assessing treatment preference for pazopanib versus sunitinib in patients with metastatic renal cell carcinoma: PISCES study. J Clin Oncol. 2014;32:1412-8.

40. van der Graaf WT, Blay JY, Chawla SP, Kim DW, Bui-Nguyen B, Casali PG, et al. Pazopanib for metastatic soft-tissue sarcoma (PALETTE): a randomised, double-blind, placebo-controlled phase 3 trial. Lancet. 2012;379:1879-86.

41. Kapadia S, Hapani S, Choueiri TK, WU S. Risk of liver toxicity with the angiogenesis inhibitor pazopanib in cancer patients. Acta Oncol. 2013;52:1202-12.

42. Frangie C, Lefaucheur C, Medioni J, Jacquot C, Hill GS, Nochy D. Renal thrombotic microangiopathy caused by anti-VEGF-antibody treatment for metastatic renal-cell carcinoma. Lancet Oncol. 2007;8:177-8.

43. Eremina V, Jefferson JA, Kowalewska J, Hochster H, Haas M, Weisstuch J, et al. VEGF inhibition and renal thrombotic microangiopathy. N Engl J Med. 2008;358:1129-36

44. Kapiteijn E, Brand A, Kroep J, Gelderblom H. Sunitinib induced hypertension, thrombotic microangiopathy and reversible posterior leukencephalopathy syndrome. Ann Oncol. 2007;18:1745-7.

45. Bruce JY, Kolesar JM, Hammers H, Stein MN, Carmichael L, Eickhoff J, et al. A phase I pharmacodynamic trial of sequential sunitinib with bevacizumab in patients with renal cell carcinoma and other advanced solid malignancies. Cancer Chemother Pharmacol. 2014;73:485-93.

46. Tewari KS, Sill MW, Long HJ III, Penson RT, Huang H, Ramondetta LM, et al. Improved survival with bevacizumab in advanced cervical cancer. $N$ Engl J Med. 2014:370:734-43.

\section{Submit your next manuscript to BioMed Central and we will help you at every step:}

- We accept pre-submission inquiries

- Our selector tool helps you to find the most relevant journal

- We provide round the clock customer support

- Convenient online submission

- Thorough peer review

- Inclusion in PubMed and all major indexing services

- Maximum visibility for your research

Submit your manuscript at www.biomedcentral.com/submit
Biomed Central 